\title{
Single vs. Double Dose Iron Supplementation for Prevention of Iron Deficiency Anemia in Twin Pregnancy: A Randomized Controlled Clinical Trial
}

\author{
Ahmed Mohammed Abbas ${ }^{1 *}$, Manal Mahmoud Elhalwagy ${ }^{2}$, Khaled Afifi', Khaled Ibrahim¹, \\ Mohamed Samir Sweed ${ }^{1}$
}

${ }^{1}$ Obstetrics \& Gynecology, Ain Shams University, Cairo, Egypt

${ }^{2}$ Obstetrics \& Gynecology, Helwan General Hospital, Cairo, Egypt

Email: ^ahmedmams@hotmail.com

How to cite this paper: Abbas, A.M., Elhalwagy, M.M., Afifi, K., Ibrahim, K. and Sweed, M.S. (2020) Single vs. Double Dose Iron Supplementation for Prevention of Iron Deficiency Anemia in Twin Pregnancy: A Randomized Controlled Clinical Trial. Open Journal of Obstetrics and Gynecology, 10, 1788-1802.

https://doi.org/10.4236/ojog.2020.10120161

Received: November 25, 2020

Accepted: December 28, 2020

Published: December 31, 2020

Copyright () 2020 by author(s) and Scientific Research Publishing Inc. This work is licensed under the Creative Commons Attribution International License (CC BY 4.0).

http://creativecommons.org/licenses/by/4.0/ (c) (i) Open Access

\begin{abstract}
Introduction: It is estimated that about $18 \%$ of pregnant women suffer from iron deficiency anemia throughout their whole pregnancy. In twin pregnancy, owing to the relatively greater feto-placental requirements and greater expansion in maternal plasma volume and red cell mass, iron requirements are magnified 1.8 times compared to singleton pregnancies. However, for prevention of iron deficiency in twin pregnancy, only sparse data exist regarding the sufficiency of the standard antenatal iron supplementation dose used in singleton pregnancies to meet the increased iron demand. In this study, we investigate the effect of single and double dose iron supplementation for prevention of iron deficiency anemia in twin pregnancy. Methods: A randomized controlled clinical trial was conducted at our center in the period between February 2019 and October 2020, and included 450 eligible healthy non-anemic women aged 18 - 35 years, with twin pregnancy at 12 - 16 weeks of gestation. After informed consent, eligible women were randomized to receive either single dose $27 \mathrm{mg}$, or double dose $54 \mathrm{mg}$ elemental iron supplementation. Monitoring of hemoglobin concentration was done at fixed time points during gestation: at enrollment, 24 weeks, 32 weeks and before delivery. The primary outcome of the study was the incidence of iron deficiency anemia during follow up until delivery. Results: The incidence of iron deficiency anemia in the two groups did not differ significantly between the single dose group (19.1\%) and the double dose group (24.0\%). In women
\end{abstract}


who did not develop Iron Deficiency Anemia, hemoglobin concentration varied significantly along the different gestational ages during the follow up period. In contrast, they did not show an overall statistically significant difference in the hemoglobin concentrations between the single or double dose groups. Conclusion: This clinical trial did not demonstrate an added benefit for doubling prophylactic iron supplementation dose in non-anemic women with twin pregnancy.

\section{Keywords}

Iron Supplementation, Iron Deficiency Anemia, Twin Pregnancy, Hepcidin, Mucosal Block

\section{Introduction}

It is estimated that about $18 \%$ of pregnant women suffer from iron deficiency anemia (IDA) throughout their whole pregnancy; with about $29 \%$ of women affected during the third trimester [1]. This is attributed, in part, to the substantial increase in iron demands (estimated to add up to $\sim 1 \mathrm{gm}$ of elemental iron throughout the pregnancy [2]) required for normal feto-placental development and maternal physiologic adaptation to pregnancy [3]. These iron requirements are normally met by increasing dietary absorption and efflux of iron from its stores [2]. Maternal iron deficiency anemia is associated with some adverse pregnancy outcomes, including intra- and postpartum blood transfusion, preterm birth, low birth weight [4] [5] and affection of prenatal neurodevelopment and neuropsychological functions in children [6].

In twin pregnancy, owing to the relatively greater feto-placental requirements and greater expansion in maternal plasma volume and red cell mass, iron requirements are magnified 1.8 times compared to singleton pregnancies [7]. This translates to a further 2.4- to even 4-fold increase in the incidence of IDA among women with twin pregnancy [8]. However, for prevention of iron deficiency in twin pregnancy, only sparse data exist regarding the sufficiency of the standard antenatal iron supplementation dose used in singleton pregnancies to meet the increased iron demand [9]. Some expert-based recommendations advocate doubling the dose of supplemental iron in twin pregnancies to a daily dose of 60 mg elemental iron [10]. This goes with the straightforward logic of "more demand - more supplementation". However, this recommendation was not adopted by many international authorities. The World Health Organization (WHO) [11] and the American College of Obstetricians and Gynecologists (ACOG) [12] made no recommendations regarding additional iron supplementation in twin pregnancy. The British Society of Hematology (BSH) in its described as "the most aggressive approach to the diagnosis and management of iron deficiency in any national guideline" [13] identified multiple pregnancy as high risk for iron 
depletion. However, for non-anemic women with twin pregnancy, the guideline recommended either selective supplementation for those with serum ferritin < $30 \mu \mathrm{g} / \mathrm{L}$ only, or empirical supplementation with a once daily $40-80 \mathrm{mg}$ of elemental iron [14]. Besides not recommending one dose over the other, the recommended dose range is nearly comparable to the $30-60 \mathrm{mg}$ dose recommended by the World Health Organization for supplementation to all pregnant women [11].

The uncertainty behind the optimum supplemental iron dose in the prevention of iron deficiency in twin pregnancies stems in part from the scarce well-designed randomized controlled trials. However, a major impact stems from the paradigm shift over the last decades in iron supplementation from a high-dose (100 - 200 mg of ferrous iron) [15] [16] [17] [18] [19] approach to a low-dose [11] [20] or even selective [14] [21] one.

In this study, we investigate the effect of single and double dose iron supplementation for prevention of iron deficiency anemia in twin pregnancy.

\section{Materials and Methods}

\subsection{Participants}

A randomized controlled clinical trial was conducted in the antenatal care clinics of A in Shams Maternity Hospital, Cairo, Egypt in the period between February 2019 and April 2020 after approval of the hospital Ethical Review Board (ERB) in January 2019 and registration under NCT03836703 on February 19, 2019 on clinicaltrials.gov.

450 eligible healthy non-anemic women, aged 18 - 35 years, with twin pregnancy at $12-16$ weeks of gestation were enrolled in this study. Based upon the WHO [11], National Institute of Clinical Excellence (NICE) [21] and Centre of Disease Control and Prevention (CDC) [22] guidelines (and also adopted by the latest BSH guidelines [14]), a cut-off hemoglobin concentration $\geq 10.5 \mathrm{gm} / \mathrm{dL}$ was used for exclusion of anemia at enrollment. Women with persistent vomiting with pregnancy, mal-absorptive disorders, autoimmune diseases, chronic use of proton pump inhibitors and antacids, hypothyroidism or suspected hemoglobinopathies were excluded from the study. In addition, the prior use of any other multi-vitamin supplementation containing iron excluded the women from participating in the study.

After informed consent, eligible women were randomized to receive either single dose $27 \mathrm{mg}$, or double dose $54 \mathrm{mg}$ elemental iron supplementation. Supplementation was started at enrollment till time of delivery using Feroglobin ${ }^{\infty}$ capsules (Vitabiotics ${ }^{\circledast}$ Egypt for Pharmaceutical Industries, Egypt), each containing ferrous fumarate (corresponding to $27 \mathrm{mg}$ elemental iron), zinc sulphate (equivalent to $10 \mathrm{mg}$ elemental zinc), $2 \mathrm{mg}$ Vitamin B6, copper Sulphate (equivalent to $900 \mathrm{mcg}$ of elemental copper), $2 \mathrm{mcg}$ Vitamin B12 and $500 \mathrm{mcg}$ folic Acid. Women were instructed to take the capsules preferably on empty stomach 
in the morning, and 2 hours apart from dairy products, calcium supplements and tannates. Women receiving double dose supplementation were instructed to take one capsule at once, 12 hours apart.

\subsection{Follow up during Antenatal Care}

Follow up visits were arranged every 2 weeks until delivery. Besides routine antenatal care, compliance was checked by counting the empty pill packages during each follow up visit. The participant was considered non-compliant if more than three doses were missed during any two-week interval, and excluded from completing the trial thereafter. In addition, surveillance for the incidence of possible adverse drug effects was conducted at every visit, including vomiting, abdominal pain, constipation (defined as bowel motions fewer than her regular habit over a one-week period or hard dry stools causing painful and difficult defecation), and black staining of the stools.

Monitoring of hemoglobin concentration was done at fixed time points during gestation: at enrollment, 24 weeks, 32 weeks and before delivery. Women who developed iron deficiency anemia in either groups (defined as hemoglobin concentration below $10.5 \mathrm{gm} / \mathrm{dL}$ or $11 \mathrm{gm} / \mathrm{dL}$ during second and third trimesters respectively [11], together with serum ferritin $<30 \mu \mathrm{g} / \mathrm{L}$ [23]) were excluded from completing the study and converted to therapeutic iron supplementation or intravenous iron therapy. Women who developed preeclampsia (due to associated volume contraction and hemoconcentration), or had recurrent and/or significant hemorrhage (either antepartum or due to any other etiologies) were also excluded from the study.

The primary outcome of the study was the incidence of iron deficiency anemia during follow up until delivery. Secondary outcomes include the hemoglobin concentration in non-anemic women throughout the follow up period and the incidence of adverse drug reactions.

\subsection{Statistical Analysis}

Data were analyzed using SPSS version 24.0 (SPSS Inc, Chicago, IL, USA). Data were analyzed on intention-to-treat basis. Parametric numerical data were presented as mean \pm standard deviation; whereas non-parametric numerical data were presented as median with interquartile range. Categorical data were presented as number and percentage. Two-group comparisons for numerical data were done using the Student $t$ test for parametric data and using the Mann-Whitney test for non-parametric data. Categorical data were compared using Chi-square test or Fisher exact test. Repeated measure analysis of follow-up data of hemoglobin concentration was done using repeated measure factorial analysis of variance (ANOVA) with post-hoc analysis using Sidak's multiple comparisons test. Effect sizes were estimated for continuous variables using mean difference and its $95 \%$ confidence interval (CI), and for categorical data using relative risk, its 95\% CI and number needed to treat/harm (if significant), with the latter being expressed 
according to the terminology proposed by Douglas Altman. [24] Significance level was set at $\mathrm{p} \leq 0.05$.

\subsection{Sample Size Justification}

Up to our knowledge, scarce data exist regarding the impact of single vs. double dose prophylactic iron supplementation in twin pregnancy for prevention of IDA. Also, no data exist regarding the prevalence of IDA among Egyptian women with twin pregnancy. However, according to Abu Salem et al. [25], the prevalence of iron deficiency anemia among Egyptian pregnant women was estimated to be $52.5 \%$. Assuming that Egyptian women with twin pregnancy would have at least a comparable prevalence of IDA, a minimal sample size of 366 women is needed to detect at least $15 \%$ reduction in this prevalence by double iron supplementation. Sample size was calculated using $G^{\star}$ Power $^{\circledR}$ version 3.1.9.2, setting the power at 0.8 and the significance level $(\alpha)$ at 0.05 . Assuming a drop-out rate of $20 \%$, a total drop-out inflated sample size of approximately 450 women will be needed to be randomized into the two groups.

\section{Results}

A total of 450 non-anemic women with twin pregnancy were randomized to either single or or double dose iron supplementation. 72 women in the single dose group and 91 women in the double dose group were excluded during the course of the study, as shown in the CONSORT flow diagram (Figure 1). However, they were included in the statistical analysis as per intention-to-treat principle. A summary of basic demographic and clinical properties of the two groups, including age, body mass index, parity, and gestational and hemoglobin concentration age at enrollment, are shown in Table 1.

The incidence of iron deficiency anemia in the two groups did not differ significantly between the single dose group (19.1\%) and the double dose group (24.0\%), with a risk ratio of 1.26 and a $95 \%$ confidence interval ranging from 0.88 to 1.79 (Table 2 and Figure 2). In women who did not develop IDA, hemoglobin concentration varied significantly along the different gestational ages during the follow up period (in consistence with the maternal hematological adaptation during pregnancy). In contrast, they did not show an overall statistically significant difference in the hemoglobin concentrations between the single or double dose groups. On post hoc analysis, no significant differences were found between both groups at any of the follow up points except before delivery (mean difference: $0.10 \mathrm{gm} / \mathrm{dL}, 95 \% \mathrm{CI}$ : $0.002-0.20$ ). However, in addition to the doubtful clinical importance of such difference, the fact that it is confounded by the variable time of delivery should be taken in consideration (Table 3).

Adverse drug effects were more common with the double dose supplementation compared to single dose supplementation, including noncompliance, constipation and black staining of the stools (Table 4). 
Non-anemic women with twin pregnancy assessed for eligibility [ $\mathrm{n}=552$ ]

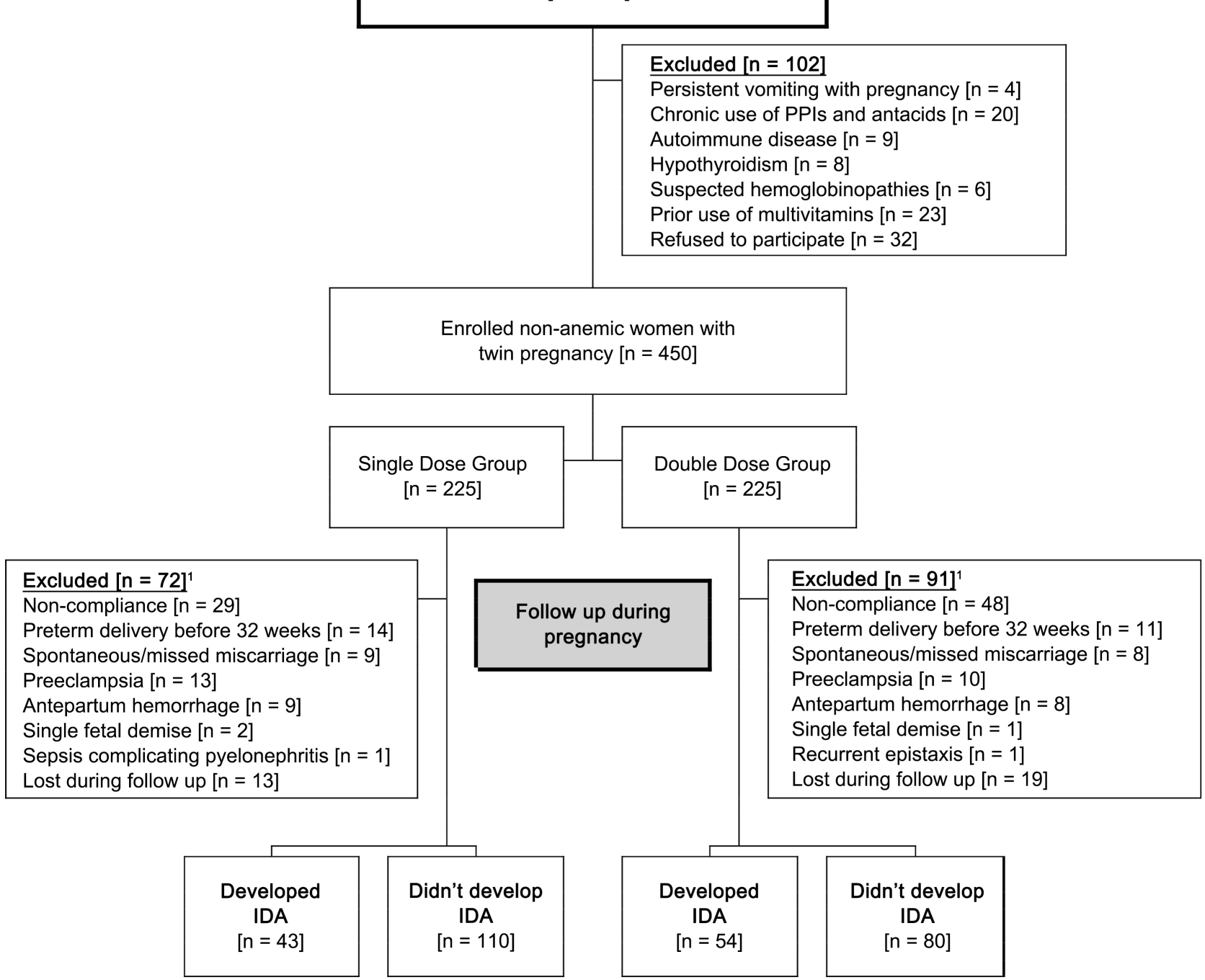

Figure 1. CONSORT 2010 flow diagram showing the recruitment and handling of the study population during the course of the study. ${ }^{1}$ It should be noted the considerable overlap in the causes of exclusion in the recruited women, e.g. some women were excluded due to preeclampsia that was complicated by placental abruption and single fetal demise necessitating preterm delivery. Abbreviations. PPIs proton pump inhibitors, IDA iron deficiency anemia.

Table 1. Basal demographic, clinical and laboratory characteristics of both groups.

\begin{tabular}{lcc}
\hline & Single Dose Group & Double Dose Group \\
\hline Age $(\mathrm{Yrs})$ & $28.73 \pm 2.77$ & $28.61 \pm 3.02$ \\
BMI $\left(\mathrm{Kg} / \mathrm{m}^{2}\right)$ & $24.05 \pm 3.44$ & $25.47 \pm 3.35$ \\
Parity & & $112(49.8 \%)$ \\
$\quad$ Nulliparous & $104(46.2 \%)$ & $113(50.2)$ \\
$\quad$ Multipara & $121(53.8 \%)$ & $14^{+3}\left(13^{+2}-15\right)$ \\
Gestational age at enrollment (wks) & $14^{+1}\left(13-14^{+6}\right)$ & $12.09 \pm 0.54$ \\
Hemoglobin concentration at enrollment $(\mathrm{gm} / \mathrm{dL})$ & $12.16 \pm 0.51$ & \\
\hline
\end{tabular}




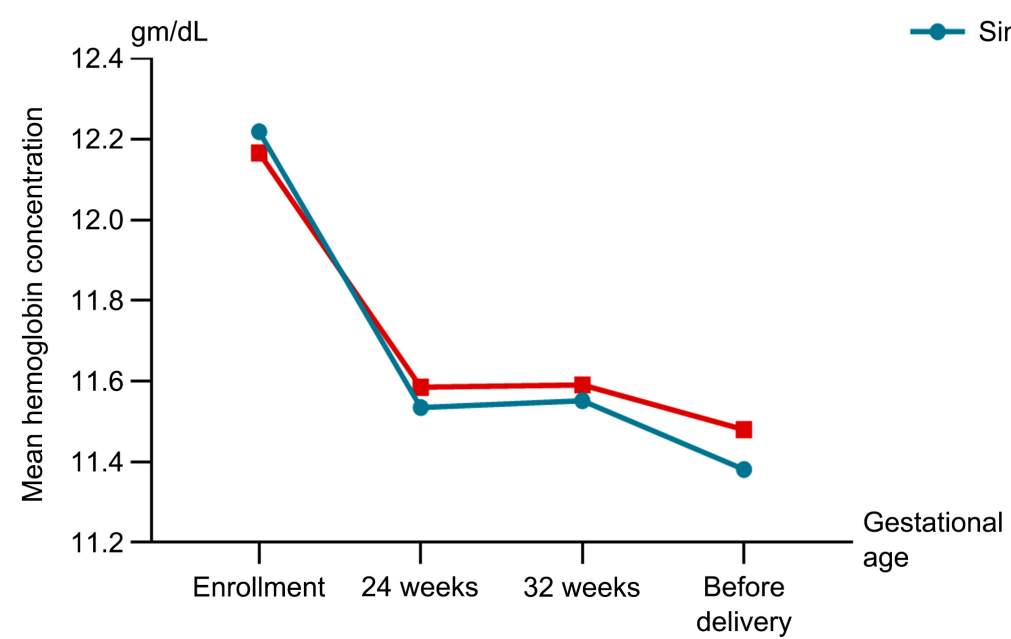

Figure 2. Line graph showing the mean hemoglobin concentration in the non-anemic women at the different gestational ages with single and double dose iron supplementation.

Table 2. Comparison between the two groups regarding incidence of iron deficiency anemia during the follow up period.

\begin{tabular}{ccccc}
\hline & Single Dose Group & Double Dose Group & P & RR (95\%CI) \\
\hline IDA & $43 / 225(19.1 \%)$ & $54 / 225(24.0 \%)$ & 0.21 & $1.26(0.88-1.79)$ \\
\hline
\end{tabular}

Abbreviation IDA: iron deficiency anemia.

Table 3. Comparison between the non-anemic women in the two groups regarding mean hemoglobin concentration (gm/dL) at different gestational ages.

\begin{tabular}{|c|c|c|c|c|c|}
\hline \multirow{2}{*}{ Time } & \multirow{2}{*}{$\begin{array}{l}\text { Single Dose Group } \\
\quad[\mathrm{n}=110]\end{array}$} & \multirow{2}{*}{$\begin{array}{l}\text { Double Dose Group } \\
\qquad[\mathrm{n}=80]\end{array}$} & \multirow{2}{*}{$\mathrm{P}$} & \multicolumn{2}{|c|}{ Post-hoc analysis } \\
\hline & & & & Mean difference $(95 \% \mathrm{CI})^{\mathrm{a}}$ & Adjusted P \\
\hline Enrollment & $12.22 \pm 0.37$ & $12.16 \pm 0.49$ & & $-0.054(-0.22-0.11)$ & 0.89 \\
\hline 24 weeks & $11.53 \pm 0.52$ & $11.58 \pm 0.62$ & $\begin{array}{l}\text { Group effect: } 0.26 \\
\text { Time effect: }<0.001\end{array}$ & $0.051(-0.17-0.27)$ & 0.96 \\
\hline 32 weeks & $11.55 \pm 0.26$ & $11.59 \pm 0.45$ & $\begin{array}{c}\text { Group } \times \text { Time } \\
\text { interaction: } 0.36\end{array}$ & $0.039(-0.10-0.18)$ & 0.93 \\
\hline Before delivery & $11.38 \pm 0.19$ & $11.48 \pm 0.29$ & & $0.10(0.002-0.20)$ & 0.04 \\
\hline
\end{tabular}

${ }^{a}$ Reported as mean hemoglobin concentration in double dose group, single dose group.

Table 4. Comparison between the two groups regarding incidence of adverse drug effects.

\begin{tabular}{cccccc}
\hline & $\begin{array}{c}\text { Single Dose Group } \\
{[\mathrm{n}=225]}\end{array}$ & $\begin{array}{c}\text { Double Dose Group } \\
{[\mathrm{n}=225]}\end{array}$ & $\mathrm{P}$ & $\mathrm{RR}(95 \% \mathrm{CI})$ & $\mathrm{NNT}_{\text {(Harm) }}(95 \% \mathrm{CI})$ \\
\hline Noncompliance & $29(12.9 \%)$ & $48(21.3 \%)$ & 0.02 & $1.66(1.09-2.53)$ & $11.8(65.4-6.51)$ \\
Nausea/Vomiting & $7(3.11 \%)$ & $11(4.89 \%)$ & 0.34 & $1.57(0.62-3.98)$ & - \\
Constipation & $24(10.7 \%)$ & $41(18.2 \%)$ & 0.03 & $1.71(1.07-2.73)$ & $13.2\left(91.1_{\text {(Harm) }}-7.13_{\text {(Harm) }}\right)$ \\
Abdominal pain & $9(4.0 \%)$ & $14(6.2 \%)$ & 0.29 & $1.56(0.68-3.52)$ & - \\
Black staining of the stools & $36(16.0 \%)$ & $68(30.2 \%)$ & $<0.001$ & $1.89(1.32-2.71)$ & $7.0\left(15.2_{\text {(Harm) }}-4.56_{\text {(Harm) }}\right)$ \\
\hline
\end{tabular}




\section{Discussion}

Paradoxically, this study failed to demonstrate a dose-response relationship between prophylactic iron supplementation dose and incidence of IDA in twin pregnancies. Compared to the single dose, the double supplemental iron dose did not significantly lower the incidence of IDA, nor increase the hemoglobin concentration in pregnancies not complicated by IDA. Comparable results were reported in the setting of both non-anemic twin [26] and single pregnancies [27] [28], and also in the setting of iron deficiency with [29] or without pregnancy [30].

Estimates of iron demand during pregnancy range from $4 \mathrm{mg} /$ day in the second trimester to $6 \mathrm{mg} /$ day in the third trimester [31] that might reach in the last 6 - 8 weeks of gestation to as much as $10 \mathrm{mg} /$ day [32]. These demands are further magnified 1.8 times in twin pregnancies [7]. In this study, we used $27 \mathrm{mg}$ and $54 \mathrm{mg}$ of supplemental elemental iron in single and double dose groups respectively, in accordance with the recommendations of the World Health Organization that all pregnant women should be supplemented with $30-60 \mathrm{mg}$ of elemental iron daily, that is increased to $120 \mathrm{mg}$ daily if anemia is diagnosed during pregnancy [11]. It is evident that these prophylactic supplementation doses are higher than the highest estimated daily iron demand by at least threeor six-folds respectively, disregarding any contribution from maternal iron stores. However, over the decades, these mega doses were used relying on the fact that treatment with oral iron salts is far from ideal. [33], with only a small fraction (not exceeding 10\% - 20\%) of the whole ingested elemental iron is absorbed [34] [35] [36]. Hence, the prevailing philosophy of increasing the ingested dose in order to increase the absolute amount of absorbed iron into the circulation.

However, a paradigm shift in iron therapeutics was set up by the discovery of the role of the hepcidin-ferroportin axis in iron homeostasis. It was established that bioavalability of oral iron therapy depends not only on dietary factors and integrity of the intestinal mucosa [37], but also on hepcidin levels. [33] Typically, in iron deficiency anemia, hepcidin levels are very low or even undetectable. Appropriately suppressed hepcidin levels prevent internalization and degradation of ferroportin from the basolateral membrane of enterocytes, thus allowing maximal ferroportin activity with resulting maximal iron flux into the plasma. In contrast, in iron replete states, rising hepcidin binds to ferroportin, promoting its internalization and degradation, culminating in preventing iron flux into plasma [38]. In short, our understanding of intestinal handling of iron changed from being a poorly permeable barrier, which we can overcome by increasing the iron dose; to a dynamically permeable barrier that can regulate iron absorption regardless of the iron dose. In fact, it seems that the commonly used supplemental iron doses cover well and much exceed the requirements of non-anemic singleton and twin pregnancies, and even anemic pregnancies. The latter is evident in the declining recommended therapeutic iron doses for IDA in pregnancy from $120 \mathrm{mg}$ in the $2016 \mathrm{WHO}$ recommendations [11] to only $40-80 \mathrm{mg}$ in the 
2020 BSH guidelines [14]. Actually, in most cases, failure of oral iron therapy is not due to low supplementation dose, but rather due to other causes, including primary gastrointestinal disorders (e.g. Helicobacter pylori infection and celiac disease), ongoing blood loss, concomitant inflammation leading to hepcidin-mediated restriction of iron flux into plasma, and genetic iron-refractory iron deficiency [39]. During pregnancy, the increased iron demand is likely offset by the enhanced intestinal absorptive capacity mediated by pregnancy-induced hepcidin suppression [2]. This makes better use of the portion of the supplemented iron that is unabsorbed under normal circumstances, without the need for increasing supplementation dose.

In fact, double iron dosing might be detrimental to the process of iron supplementation. Beside remaining unabsorbed in the face of tight hepcidin regulation and absence of added clinical efficacy, it is thought that higher iron dosing might paradoxically interfere with intestinal iron absorption. It is well established that hepcidin is regulated by at least three basic stimuli: circulating and stored iron levels, erythropoietic activity and pro-inflammatory stimuli [2]. The theory argues that absorption of a large-dose of iron will increase plasma iron levels and subsequently hepcidin levels, which will interfere with absorption of next dose(s) [34]. Radioactive iron absorption studies in iron-depleted dogs demonstrated relative mucosal block of iron absorption following iron administration [40]. Also, in the study of Moretti and his colleagues [41], daily iron supplementation to non-anemic iron-depleted young women at doses $60,80,160$ and $240 \mathrm{mg}$ of elemental iron resulted in a statistically significant elevation in hepcidin level for at least 24-hours, which translated to a 35\% - 45\% decline in the absorbed fraction of the next dose. This effect was less evident with daily supplementation of $40 \mathrm{mg}$ of elemental iron (only $20 \%$ decline). Thus, despite the increase in the absolute iron absorption with increasing the supplementation dose, fractional absorption is markedly decreased. A six-fold increase in iron dose (from $40 \mathrm{mg}$ to $240 \mathrm{mg}$ ) resulted in only three-fold increase in iron absorption (from $6.7 \mathrm{mg}$ to $18.1 \mathrm{mg}$ ), with the consequent marked increase in the unabsorbed fraction with dose escalation. This paradoxical interference might further be augmented during pregnancy due to the physiological pregnancy-induced suppression of maternal hepcidin during the second and third trimesters [2], which entails, at least theoretically, a higher initial influx of iron into the blood leading to a subsequent more profound hepcidin elevation and mucosal block.

Being a cheap drug, determining the least effective iron supplementation dose might not be valuable in terms of cost-effectiveness; however, the impact on the adverse effects profile might be substantial. First, the higher the iron dose, the greater the remaining unabsorbed portion contributing to its direct toxic free radical effect on the intestinal mucosa [33] [42]. As reported in this study and others [26], the incidence of gastrointestinal adverse effects increases with the increase in iron dose. Second, excess unabsorbed iron reaching the colonic lumen causes intestinal stress [43], restraining the growth of the colonizing gut 
microbial community except for the virulent pathogens that can tolerate this iron-richoxidatively stressful mileu [44] [45]. Third, with high iron doses, the faster elevation in serum iron rapidly saturates circulating transferrin, and enhances the formation of non-transferrin bound iron (NTBI) with the subsequent increase in the labile iron pool, which may induce oxidative and nitrosativestress with their pregnancy complications [46]. Fourth, iron supplementation, especially at high doses, might negatively affect the absorption of some essential divalent cations, e.g. zinc, copper, magnesium, manganese, chromium and molybdenum [47] [48]. Fifth, accumulating evidence postulate a possible link between elevations in circulating iron and the development of gestational diabetes [49] [50] [51] [52] and pregnancy-induced hypertension [53] [54] [55], and also a possible link between prenatal supraphysiologic iron exposure and the risk of development of childhood type 1 diabetes mellitus [56].

In spite of the comparable results reported by Ali and his colleagues [26] for the effect of single vs. double dose iron supplementation on the incidence of IDA and hemoglobin concentrations, they noted larger increase serum ferritin levels in the double dose group $(54.58 \mu \mathrm{g} / \mathrm{L})$ compared to the single dose group (39.69 $\mu \mathrm{g} / \mathrm{L}$ ) before delivery. Despite that serum ferritin levels of both groups are well within the normal range, two points are noteworthy. First, in our study, we opted not to rely on serum ferritin levels, as the physiological rise in acute phase proteins [57] and alterations in iron homeostasis [2] associated with pregnancy might confound the effect of iron supplementation dose on changes in serum ferritin levels. Second, it is not known whether this increment in serum ferritin is beneficial or not. Several studies noted the association between high serum ferritin levels and adverse pregnancy outcomes [58] [59] [60].

The strengths of our study include: 1) its randomized design; 2) evaluation of efficacy using a clinical outcome, rather than biochemical markers of iron status that might be affected by other confounders. However, our study is limited by the lack of standardization of maternal diet, which might have affected the outcome. However, the lengthy follow up duration rendered tracking the daily dietary iron content unrealistic. Another limitation is conferred by not differentiating between non-anemic iron-deficient women from those with adequate iron stores. However, we postulated that this would keep the trial design and results more clinically oriented, as assessment of iron stores during antenatal care is not recommended in routine clinical practice by most regulatory bodies to date [11] [14] [20] [21].

\section{Conclusion}

In conclusion, this clinical trial did not demonstrate an added benefit for doubling prophylactic iron supplementation dose in non-anemic women with twin pregnancy.

\section{Conflicts of Interest}

The authors declare no conflicts of interest regarding the publication of this paper. 


\section{References}

[1] Bailit, J., Doty, E. and Todia, W. (2007) Repeated Hematocrit Measurements in Low-Risk Pregnant Women. The Journal of Reproductive Medicine, 52, 619-622.

[2] Fisher, A.L. and Nemeth, E. (2017) Iron Homeostasis during Pregnancy. The American Journal of Clinical Nutrition, 106, 1567S-1574S. https://doi.org/10.3945/ajen.117.155812

[3] Bothwell, T.H. (2000) Iron Requirements in Pregnancy and Strategies to Meet Them. The American Journal of Clinical Nutrition, 72, 257S-264S. https://doi.org/10.1093/ajen/72.1.257S

[4] Smith, C., Teng, F., Branch, E., Chu, S. and Joseph, K.S. (2019) Maternal and Perinatal Morbidity and Mortality Associated with Anemia in Pregnancy. Obstetrics \& Gynecology, 134, 1234-1244. https://doi.org/10.1097/AOG.0000000000003557

[5] Murphy, J.F., O’Riordan, J., Newcombe, R.G., Coles, E.C. and Pearson, J.F. (1986) Relation of Haemoglobin Levels in First and Second Trimesters to Outcome of Pregnancy. Lancet, 327, 992-995. https://doi.org/10.1016/S0140-6736(86)91269-9

[6] Arija, V., Hernández-Martínez, C., Tous, M., Canals, J., Guxens, M., Fernández Barrés, S., et al. (2019) Association of Iron Status and Intake during Pregnancy with Neuropsychological Outcomes in Children Aged 7 Years: The Prospective Birth Cohort Infancia y Medio Ambiente (INMA) Study. Nutrients, 11, 2999. https://doi.org/10.3390/nu11122999

[7] Mares, M. and Casanueva, E. (2002) Comer por Tres? Lineamientos para la Alimentación y Nutrición de la Mujer con Embarazo Gemelar. Cuadernos de nutrición, 25, 280-284.

[8] Blickstein, I., Goldschmit, R. and Lurie, S. (1995) Hemoglobin Levels during Twin vs. Singleton Pregnancies. Parity Makes the Difference. The Journal of Reproductive Medicine, 40, 47-50.

[9] Shinar, S., Skornick-Rapaport, A. and Maslovitz, S. (2017) Iron Supplementation in Twin Pregnancy-The Benefit of Doubling the Iron Dose in Iron Deficient Pregnant Women: A Randomized Controlled Trial. Twin Res Hum Genet, 20, 419-424. https://doi.org/10.1017/thg.2017.43

[10] Goodnight, W. and Newman, R. (2009) Optimal Nutrition for Improved Twin Pregnancy Outcome. Obstetrics \& Gynecology, 114, 1121-1134. https://doi.org/10.1097/AOG.0b013e3181bb14c8

[11] World Health Organization (2016) WHO Recommendations on Antenatal Care for a Positive Pregnancy Experience. World Health Organization, Geneva.

[12] American College of Obstetricians and Gynecologists (2008) ACOG Practice Bulletin No. 95: Anemia in Pregnancy. Obstetrics \& Gynecology, 112, 201-207. https://doi.org/10.1097/AOG.0b013e3181809c0d

[13] Auerbach, M. and Georgieff, M.K. (2020) Guidelines for Iron Deficiency in Pregnancy: Hope Abounds. British Journal of Haematology, 188, 814-816. https://doi.org/10.1111/bjh.16220

[14] Pavord, S., Daru, J., Prasannan, N., Robinson, S., Stanworth, S. and Girling, J. (2020) UK Guidelines on the Management of Iron Deficiency in Pregnancy. British Journal of Haematology, 188, 819-830. https://doi.org/10.1111/bjh.16221

[15] Milman, N. (2006) Iron Prophylaxis in Pregnancy-General or Individual and in Which Dose? Annals of Hematology, 85, 821-828.

https://doi.org/10.1007/s00277-006-0145-x 
[16] Milman, N., Ibsen, K.K. and Christensen, J.M. (1987) Serum Ferritin and Iron Status in Mothers and Newborn Infants. Acta Obstetricia et Gynecologica Scandinavica, 66, 205-211. https://doi.org/10.3109/00016348709020748

[17] Romslo, I., Haram, K., Sagen, N. and Augensen, K. (1983) Iron Requirement in Normal Pregnancy as Assessed by Serum Ferritin, Serum Transferrin Saturation and Erythrocyte Protoporphyrin Determinations. British Journal of Obstetrics and Gynaecology, 90, 101-107. https://doi.org/10.1111/j.1471-0528.1983.tb08891.x

[18] Sjöstedt, J.E., Manner, P., Nummi, S. and Ekenved, G. (1977) Oral Iron Prophylaxis during Pregnancy-a Comparative Study on Different Dosage Regimens. Acta Obstetricia et Gynecologica Scandinavica, 56, 3-9.

https://doi.org/10.1111/aogs.1977.56.s60.3

[19] Svanberg, B. (1975) Absorption of Iron in Pregnancy. Acta Obstetricia et Gynecologica Scandinavica, 54, 5-27. https://doi.org/10.3109/00016347509156328

[20] FIGO Working Group on Good Clinical Practice in Maternal-Fetal Medicine (2019) Good Clinical Practice Advice: Iron Deficiency Anemia in Pregnancy. International Journal of Gynecology \& Obstetrics, 144, 322-324. https://doi.org/10.1002/ijgo.12740

[21] National Institute for Health and Care Excellence (Grande-Bretagne) (2019) Antenatal Care for Uncomplicated Pregnancies. National Institute for Health and Care Excellence, London. http://www.ncbi.nlm.nih.gov/books/NBK552849/

[22] Centers for Disease Control and Prevention (1998) Recommendations to Prevent and Control Iron Deficiency in the United States. Morbidity and Mortality Weekly Report, 47, i-29.

[23] Pavord, S., Myers, B., Robinson, S., Allard, S., Strong, J. and Oppenheimer, C. (2012) UK Guidelines on the Management of Iron Deficiency in Pregnancy. British Journal of Haematology, 156, 588-600. https://doi.org/10.1111/j.1365-2141.2011.09012.x

[24] Altman, D.G. (1998) Confidence Intervals for the Number Needed to Treat. BMJ, 317, 1309-1312. https://doi.org/10.1136/bmj.317.7168.1309

[25] Abu Salem, M., Mahrous, O., El Shazly, H., Ibrahim, R. and Al-Oshari, S. (2016) Epidemiology of Iron-Deficiency Anemia among Pregnant Women in Menoufia Governorate, Egypt and Taiz Governorate, Yemen: A Comparative Study. Menoufia Medical Journal, 29, 1005-1011.

[26] Ali, M.K., Abbas, A.M., Abdelmagied, A.M., Mohammed, G.E. and Abdalmageed, O.S. (2017) A Randomized Clinical Trial of the Efficacy of Single versus Double-Daily Dose of Oral Iron for Prevention of Iron Deficiency Anemia in Women with Twin Gestations. The Journal of Maternal-Fetal \& Neonatal Medicine, 30, 2884-2889. https://doi.org/10.1080/14767058.2016.1266478

[27] Milman, N., Byg, K.-E., Bergholt, T., Eriksen, L. and Hvas, A.-M. (2006) Body Iron and Individual Iron Prophylaxis in Pregnancy-Should the Iron Dose Be Adjusted According to Serum Ferritin? Annals of Hematology, 85, 567-573.

https://doi.org/10.1007/s00277-006-0141-1

[28] Milman, N., Bergholt, T., Eriksen, L., Byg, K.-E., Graudal, N., Pedersen, P., et al. (2005) Iron Prophylaxis during Pregnancy-How Much Iron Is Needed? A Randomized Dose-Response Study of 20-80 mg Ferrous Iron Daily in Pregnant Women. Acta Obstetricia et Gynecologica Scandinavica, 84, 238-247. https://doi.org/10.1111/j.0001-6349.2005.00610.x

[29] Shinar, S., Skornick-Rapaport, A. and Maslovitz, S. (2017) Iron Supplementation in Singleton Pregnancy: Is There a Benefit to Doubling the Dose of Elemental Iron in 
Iron-Deficient Pregnant Women? A Randomized Controlled Trial. Journal of Perinatology, 37, 782-786. https://doi.org/10.1038/jp.2017.43

[30] Rimon, E., Kagansky, N., Kagansky, M., Mechnick, L., Mashiah, T., Namir, M., et al. (2005) Are We Giving Too Much Iron? Low-Dose Iron Therapy Is Effective in Octogenarians. The American Journal of Medicine, 118, 1142-1147. https://doi.org/10.1016/j.amjmed.2005.01.065

[31] Gassmann, B. (1991) Requirements of Vitamin A, Iron, Folate and Vitamin B12. Report of Joint FAO/WHO Expert Consultation. 107 Seiten, 5 Abb., 24 Tab. Food and Agriculture Organization of the United Nations, Rome 1988. Food/Nahrung, 35, 20. https://doi.org/10.1002/food.19910350104

[32] Hallberg, L. (1992) Iron Balance in Pregnancy and Lactation. In: Fomon, S.J. and Zlotkin, S., Eds., Nutritional Anemias, Vol. 30, Raven Press, New York, 13-28.

[33] Girelli, D., Ugolini, S., Busti, F., Marchi, G. and Castagna, A. (2018) Modern Iron Replacement Therapy: Clinical and Pathophysiological Insights. International Journal of Hematology, 107, 16-30. https://doi.org/10.1007/s12185-017-2373-3

[34] Schrier, S.L. (2015) So You Know How to Treat Iron Deficiency Anemia. Blood, 126, 1971. https://doi.org/10.1182/blood-2015-09-666511

[35] Zimmermann, M.B. and Hurrell, R.F. (2007) Nutritional Iron Deficiency. The Lancet, 370, 511-520. https://doi.org/10.1016/S0140-6736(07)61235-5

[36] Tondeur, M.C., Schauer, C.S., Christofides, A.L., Asante, K.P, Newton, S., Serfass, R.E., et al. (2004) Determination of Iron Absorption from Intrinsically Labeled Microencapsulated Ferrous Fumarate (Sprinkles) in Infants with Different Iron and Hematologic Status by Using a Dual-Stable-Isotope Method. The American Journal of Clinical Nutrition, 80, 1436-1444. https://doi.org/10.1093/ajcn/80.5.1436

[37] Abrams, S.A. (2004) New Approaches to Iron Fortification: Role of Bioavailability Studies. The American Journal of Clinical Nutrition, 80, 1104-1105. https://doi.org/10.1093/ajcn/80.5.1104

[38] Nemeth, E., Tuttle, M.S., Powelson, J., Vaughn, M.B., Donovan, A., McVey Ward, D., et al. (2004) Hepcidin Regulates Cellular Iron Efflux by Binding to Ferroportin and Inducing Its Internalization. Science, 306, 2090-2093. https://doi.org/10.1126/science.1104742

[39] Camaschella, C. (2015) Iron-Deficiency Anemia. New England Journal of Medicine, 372, 1832-1843. https://doi.org/10.1056/NEJMra1401038

[40] Hahn, P.F., Bale, W.F., Ross, J.F., Balfour, W.M. and Whipple, G.H. (1943) Radioactive Iron Absorption by Gastro-Intestinal Tract: Influence of Anemia, Anoxia, and Antecedent Feeding Distribution in Growing Dogs. Journal of Experimental Medicine, 78, 169-188. https://doi.org/10.1084/jem.78.3.169

[41] Moretti, D., Goede, J.S., Zeder, C., Jiskra, M., Chatzinakou, V., Tjalsma, H., et al. (2015) Oral Iron Supplements Increase Hepcidin and Decrease Iron Absorption from Daily or Twice-Daily Doses in Iron-Depleted Young Women. Blood, 126, 1981-1989. https://doi.org/10.1182/blood-2015-05-642223

[42] Lund, E.K., Wharf, S.G., Fairweather-Tait, S.J. and Johnson, I.T. (1999) Oral Ferrous Sulfate Supplements Increase the Free Radical-Generating Capacity of Feces from Healthy Volunteers. The American Journal of Clinical Nutrition, 69, 250-255. https://doi.org/10.1093/ajcn/69.2.250

[43] Kortman, G.A.M., Raffatellu, M., Swinkels, D.W. and Tjalsma, H. (2014) Nutritional Iron Turned Inside Out: Intestinal Stress from a Gut Microbial Perspective. FEMS Microbiology Reviews, 38, 1202-1234. 
https://doi.org/10.1111/1574-6976.12086

[44] Jaeggi, T., Kortman, G.A.M., Moretti, D., Chassard, C., Holding, P., Dostal, A., et al. (2015) Iron Fortification Adversely Affects the Gut Microbiome, Increases Pathogen Abundance and Induces Intestinal Inflammation in Kenyan Infants. Gut, 64, 731-742. http://dx.doi.org/10.1136/gutjnl-2014-307720

[45] Zimmermann, M.B., Chassard, C., Rohner, F., N’Goran, E.K., Nindjin, C., Alexandra, D., et al. (2010) The Effects of Iron Fortification on the Gut Microbiota in African Children: A Randomized Controlled Trial in Cote d'Ivoire. The American Journal of Clinical Nutrition, 92, 1406-1415. https://doi.org/10.3945/ajen.110.004564

[46] Koskenkorva-Frank, T.S., Weiss, G., Koppenol, W.H. and Burckhardt, S. (2013) The Complex Interplay of Iron Metabolism, Reactive Oxygen Species, and Reactive Nitrogen Species: Insights into the Potential of Various Iron Therapies to Induce Oxidative and Nitrosative Stress. Free Radical Biology and Medicine, 65, 1174-1194. https://doi.org/10.1016/j.freeradbiomed.2013.09.001

[47] Skikne, B. and Baynes, R. (1994) Iron Absorption. In: Brock, J.H., Halliday, J., Pippard, M. and Powell, L., Eds., Iron Metabolism in Health and Disease, Saunders, London, 151-187.

[48] Rossander-Hultén, L., Brune, M., Sandström, B., Lönnerdal, B. and Hallberg, L. (1991) Competitive Inhibition of Iron Absorption by Manganese and Zinc in $\mathrm{Hu}-$ mans. The American Journal of Clinical Nutrition, 54, 152-156. https://doi.org/10.1093/ajcn/54.1.152

[49] Kataria, Y., Wu, Y.X., De Hemmer Horskjær, P., Mandrup-Poulsen, T. and Ellervik, C. (2018) Iron Status and Gestational Diabetes-A Meta-Analysis. Nutrients, 10, 621. https://doi.org/10.3390/nu10050621

[50] Marí-Sanchis, A., Díaz-Jurado, G., Basterra-Gortari, F.J., de la Fuente-Arrillaga, C., Martínez-González, M.A. and Bes-Rastrollo, M. (2018) Association between Pre-Pregnancy Consumption of Meat, Iron Intake, and the Risk of Gestational Diabetes: The SUN Project. European Journal of Nutrition, 57, 939-949. https://doi.org/10.1007/s00394-017-1377-3

[51] Zhao, L., Lian, J., Tian, J.S., Shen, Y., Ping, Z.G., Fang, X.X., et al. (2017) Dietary Intake of Heme Iron and Body Iron Status Are Associated with the Risk of Gestational Diabetes Mellitus: A Systematic Review and Meta-Analysis. Asia Pacific Journal of Clinical Nutrition, 26, 1092-1106.

[52] Qiu, C., Zhang, C., Gelaye, B., Enquobahrie, D.A., Frederick, I.O. and Williams, M.A. (2011) Gestational Diabetes Mellitus in Relation to Maternal Dietary Heme Iron and Nonheme Iron Intake. Diabetes Care, 34, 1564-1569. https://doi.org/10.2337/dc11-0135

[53] Lewandowska, M., Sajdak, S. and Lubiński, J. (2019) Can Serum Iron Concentrations in Early Healthy Pregnancy Be Risk Marker of Pregnancy-Induced Hypertension? Nutrients, 11, 1086. https://doi.org/10.3390/nu11051086

[54] Jirakittidul, P., Sirichotiyakul, S., Ruengorn, C., Techatraisak, K. and Wiriyasirivaj, B. (2018) Effect of Iron Supplementation during Early Pregnancy on the Development of Gestational Hypertension and Pre-Eclampsia. Archives of Gynecology and Obstetrics, 298, 545-550. https://doi.org/10.1007/s00404-018-4821-6

[55] Ziaei, S., Norrozi, M., Faghihzadeh, S. and Jafarbegloo, E. (2007) A Randomised Placebo-Controlled Trial to Determine the Effect of Iron Supplementation on Pregnancy Outcome in Pregnant Women with Haemoglobin $\geq 13.2 \mathrm{~g} / \mathrm{dl}$. BJOG, 114, 684-688. https://doi.org/10.1111/j.1471-0528.2007.01325.x 
[56] Størdal, K., McArdle, H.J., Hayes, H., Tapia, G., Viken, M.K., Lund-Blix, N.A., et al. (2018) Prenatal Iron Exposure and Childhood Type 1 Diabetes. Scientific Reports, 8, Article No. 9067. https://doi.org/10.1038/s41598-018-27391-4

[57] Kæstel, P., Aaby, P., Ritz, C. and Friis, H. (2015) Markers of Iron Status Are Associated with Stage of Pregnancy and Acute-Phase Response, but Not with Parity among Pregnant Women in Guinea-Bissau. British Journal of Nutrition, 114, 1072-1079. https://doi.org/10.1017/S0007114515001993

[58] Editorial (2009) Non-Anaemic Pregnant Women Should not Take Iron Supplements. Prescrire International, 18, 261-262.

[59] Scholl, T.O. (2005) Iron Status during Pregnancy: Setting the Stage for Mother and Infant. The American Journal of Clinical Nutrition, 81, 1218S-1222S. https://doi.org/10.1093/ajcn/81.5.1218

[60] Lao, T.T., Tam, K.F. and Chan, L.Y. (2000) Third Trimester Iron Status and Pregnancy Outcome in Non-Anaemic Women: Pregnancy Unfavourably Affected by Maternal Iron Excess. Human Reproduction, 15, 1843-1848.

https://doi.org/10.1093/humrep/15.8.1843 